\title{
$\mathrm{SB} 5-\mathrm{B}$ 소형차 충돌속도의 상향 가능성 평가
}

\author{
김기동 ${ }^{*},{\text { 고만기 }{ }^{1}, \text { 주재웅 }}^{2}$
}

${ }^{1}$ 공주대학교 건설환경공학부, ${ }^{2}$ 한국도로공사 도로교통연구원

\section{Assessment on the Possibility of Increase of SB5-B Small Car Impact Velocity}

\author{
Kee-Dong Kim ${ }^{1^{*}}$, Man-Gi Ko ${ }^{1}$ and Jae-Woong $\mathbf{J o o}^{2}$ \\ ${ }^{1}$ Department of Civil \& Environmental Engineering, Kongju National University \\ ${ }^{2}$ Korea Expressway Corporation Research Institute
}

\begin{abstract}
요 약 SMART Highway 종방향 배리어 상위등급 SB5-B 대형차 충돌조건을 만족하면서 $120 \mathrm{~km} / \mathrm{h}$ 의 소형차충돌속도 를 $130 \mathrm{~km} / \mathrm{h}$ 로 상향시킬 수 있는 가능성이 조사되었다. 실물 충돌시험의 결과에 Calibrate된 입력 변수를 적용한 컴퓨 터 시뮬레이션을 통하여 $120 \mathrm{~km} / \mathrm{h}$ 소형차 충돌속도에 대한 차량의 종방향(longitudinal)과 횡방향(transverse) 속도변화가 $T H I V$ 한계를 만족시킬 수 있도록 다양한 배리어 모델이 개선되었고 이 과정을 통해 결정된 배리어 모델이 SB5-B 실물충돌시험을 통과하였다. 통과된 배리어 모델 slip block-out 날개의 각도를 변화시키면서 $120 \mathrm{~km} / \mathrm{h}$ 소형차 충돌속 도의 상향가능성을 유한요소해석(FEA)을 통하여 조사하고 실물차량 충돌시험을 수행하였다. 소형차충돌속도 $130 \mathrm{~km} / \mathrm{h}$ 에 대한 표준시험 여건이 갖추어 진다면 소형차 충돌속도 $130 \mathrm{~km} / \mathrm{h}$ 로 상향시킬 수 있는 가능성이 높은 것으로 조사되 었다.
\end{abstract}

\begin{abstract}
Satisfying the large car impact condition of the high level SB5-B for "SMART Highway" longitudinal barriers, the possibility of increase of the small car impact velocity from $120 \mathrm{~km} / \mathrm{h}$ to $130 \mathrm{~km} / \mathrm{h}$ was investigated. Through computer simulation using input parameters calibrated to full-scale crash test results, various longitudinal semi-rigid barrier models were improved such that for the small car impact speed of $120 \mathrm{~km} / \mathrm{h}$ the change of longitudinal and transverse velocities of the impact vehicle can satisfy the THIV limit. The barrier model determined through this process satisfied the performance assessment criteria for SB5-B impact conditions. Varying the wing angle of slip block-outs of the passed barrier model, the possibility of increase of the small car impact velocity was investigated by FEA and a full-scale crash test was conducted. It has been shown that the possibility to increase the small car impact speed to $130 \mathrm{~km} / \mathrm{h}$ is high if the test facility condition for $130 \mathrm{~km} / \mathrm{h}$ impact velocity is better equipped.
\end{abstract}

Key Words : FEA, Impact velocity, Longitudinal semi-rigid barriers, SB5-B Impact Condition

\section{1. 서론}

SMART Highway 사업은 미래의 변화에 효과적으로 대응할 수 있도록 고속도로의 안전성, 이동성, 그리고 편 리성을 증진시키기 위하여 IT를 기반으로 하는 교통운영
기술, 도로상황을 인식하는 차량 지능화 기술, 그리고 높 은 설계속도에 필요한 도로기술 등을 연구하는 사업이다. 본 연구는 높은 설계속도에 관한 도로기술 중에서 도로 설계속도의 증가에 상응하는 배리어 충돌조건과 배리어 에 관한 것이다.

본 논문은 국토교통부 건설기술혁신사업(07-기술혁신-A01)의 연구비 지원으로 수행되었습니다.

"Corresponding Author : Kee-Dong Kim(Kongju National Univ.)

Tel: +82-41-521-9306 email: kkkim@kongju.ac.kr

Received May 20, 2013

Revised June 3, 2013

Accepted June 7, 2013 
SMART Highway의 종방향 배리어 상위 등급(SB5-B) 충돌조건으로 소형차에 대하여 $900 \mathrm{~kg}$ 의 충돌차량, $120 \mathrm{~km} / \mathrm{h}$ 의 충돌속도, 그리고 $20^{\circ}$ 의 충돌각도가 사용되었 고 대형차에 대해서는 $14000 \mathrm{~kg}$ 의 충돌차량, $85 \mathrm{~km} / \mathrm{h}$ 의 충 돌속도, 그리고 $15^{\circ}$ 의 충돌각도가 사용되었다. SB5-B 소 형차 충돌속도는 "Criteria for high design speed facilities"[1]에 제시된 도로설계속도 $140 \mathrm{~km} / \mathrm{h}$ 에 대한 $118 \mathrm{~km} / \mathrm{h}$ 의 소형차 충돌속도를 고려하여 결정된 것이다.

도로안전시설(roadside safety features)의 실물 충돌 시험 을 위한 충돌조건은 일반적으로 발생 가능한 최악의 조건 (worst practical conditions)과 과도한 경제적인 부담 없이 활 용할 수 있는 기술로 실현 가능한 성능 수준(performance level)을 고려하여 결정된다. 본 연구에서는 위의 SMART Highway 상위등급(SB5-B) 소형차 충돌조건이 현실 가능한 최악의 조건인지 검토하고 SB5-B 대형차 충돌조건을 만족 하면서 $120 \mathrm{~km} / \mathrm{h}$ 의 소형차충돌조건을 $130 \mathrm{~km} / \mathrm{h}$ 로 상향시킬 수 있는 가능성을 조사하고자 하였다.

\section{2. 컴퓨터 시뮬레이션을 위한 입력변수의 Calibration}

본 연구에서는 실물 충돌시험의 결과에 calibrate된 주 요 입력변수를 적용한 컴퓨터 시뮬레이션을 수행하면서 종방향 속도 $\left(V_{x}\right)$ 와 횡방향 속도( $\left.V_{y}\right)$ 변화가 Theoretical Head Impact Velocity(THIV) 한계값을 만족시킬 수 있도 록 해석모델을 개선하고 SB5-B 소형차 충돌조건의 상향 가능성을 조사하였다. 종방향 반강성 배리어의 경우에 snagging과 pocketing이 방지되도록 Block-Out이 적절히 설계된다면 Post-impact Head Deceleration $(P H D)$ 값이 설계를 좌우하는 중요한 변수로 작용하지 않는다. 따라서 본 연구에서는 $T H I V$ 발생시간 $t_{T}$ 에서의 차량 종방향 속 도 $\left(V_{x}\left(t_{T}\right)\right)$ 와 횡방향 속도 $\left(V_{y}\left(t_{T}\right)\right)$ 의 합속도 $\left(\sqrt{V_{x}^{2}\left(t_{T}\right)+V_{y}^{2}\left(t_{T}\right)}\right)$ 로 정의되는 $T H I V$ 를 중요 변수 로 고려하여 배리어 모델을 개선하였다. 여기서, $t_{T}$ 는

$V_{y}$ 속도변화를 나타내는 $V_{y}$ 곡선과 초기 충돌속도 사 이의 면적이 $0.3 \mathrm{~m}$ 이 되는 시간을 나타낸다.

$\mathrm{FEA}$ (Finite Element Analysis)는 충돌해석에 광범위하 게 사용되고 있는 3-D 비선형 동적 해석프로그램인 LS-DYNA[2]를 사용하여 수행되었다. 차량 모델은 미국 의 National Crash Analysis Center(NCAC)에서 공개한 Geo Metro Model[3]이 사용되었다. Table 1에 Geo Metro 차량 해석모델의 형상과 구성요소가 나타나 있다. 배리어
의 모든 구성요소에 탄성-완전소성 응력-변형율 관계가 적용되었다. 지주를 제외한 강재 재료모델은 $245 \mathrm{Mpa}$ 의 항복강도와 $210,000 \mathrm{Mpa}$ 의 탄성계수가 적용되었다. Post 와 지반의 재료특성은 정적 지주강도 시험의 하중-변위 관계에 calibration을 통하여 결정되었다. 보, 지주, 그리 고 Block-Out의 모델에 사용된 해석요소의 수는 mesh refinement 과정을 통하여 결정되었다. FEA에 적용된 차 량과 배리어 모델의 주요 입력자료와 보다 자세한 Calibration 과정은 참고문헌[4]에 나타나있다. Fig. 1에는 Test와 FEA결과가 나타나있는데 이 그림으로부터 FEA 가 차량 횡방향 속도 $V_{x}$ 와 종방향 속도 $V_{y}$ 를 상당히 정 확하게 예측한다는 것을 볼 수 있다.

[Table 1] Vehicle(Geo Metro) of FEA model

\begin{tabular}{c|c}
\hline \\
\hline Element Type & Number of Elements \\
\hline Solid & 1,209 \\
\hline Beam & 2 \\
\hline Shell & 191,980 \\
\hline 기타 & 8 \\
\hline Total & 193,199 \\
\hline
\end{tabular}

Fig. 2에 나타나 있는 다양한 배리어 모델에 대하여 $\mathrm{FEA}$ 를 수행하여 SB5-B 소형차 충돌조건을 만족시킬 수 있는 배리어 설계를 조사하고 최적 모델을 결정한 후에 최적 모델을 이용하여 SB5-B 소형차 충돌조건의 상향 가 능성을 조사하였다.

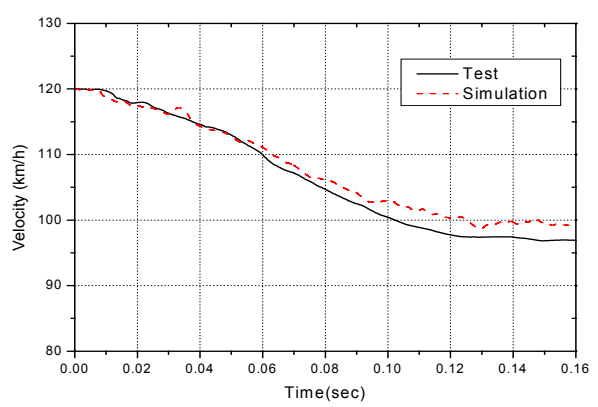

(a) 


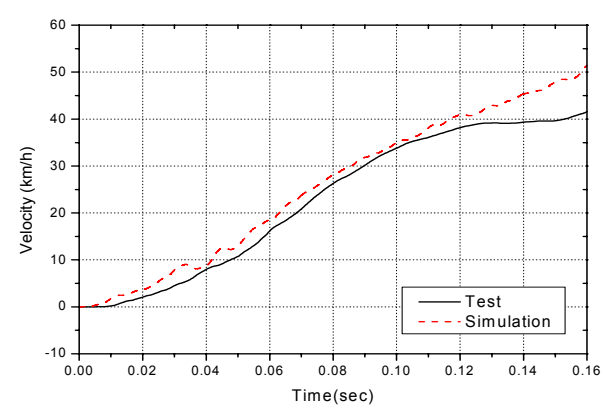

(b)

[Fig. 1] Comparison of test and simulation:

(a) Longitudinal velocity variations;

(b) Transverse velocity variations.

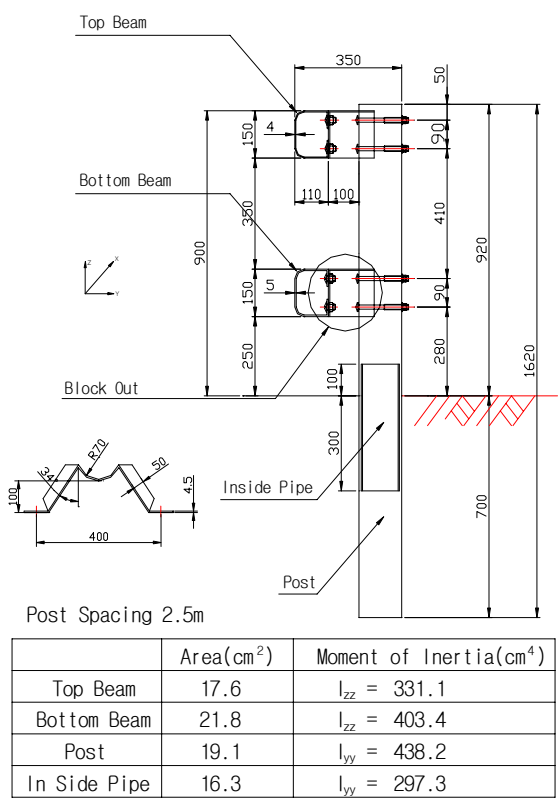

(a)
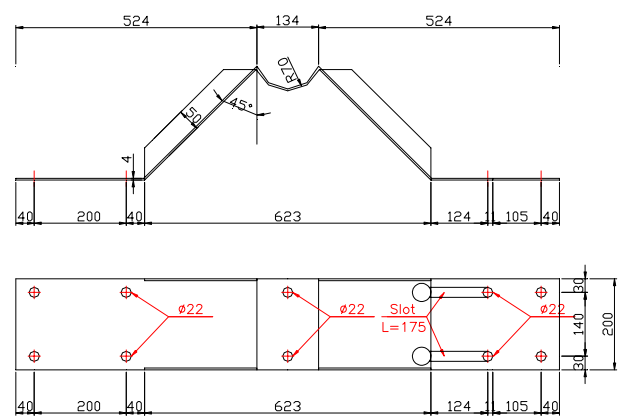

(b)

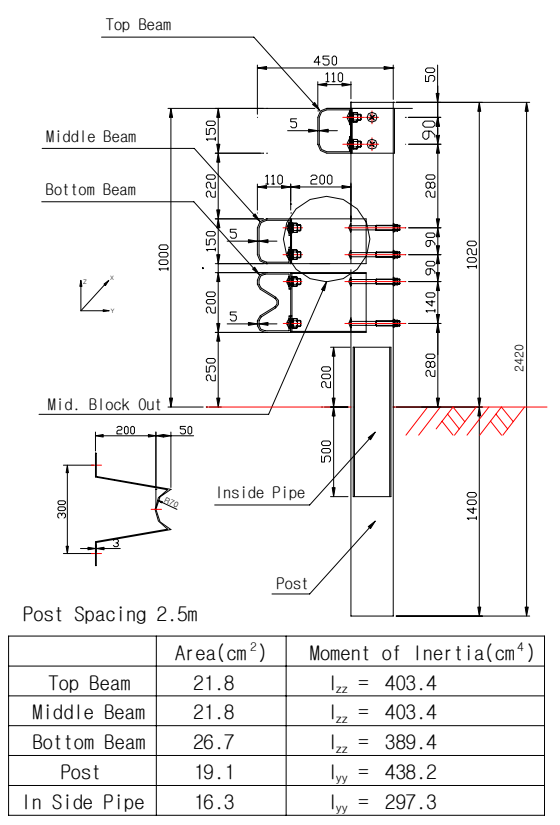

(c)

[Fig. 2] Sections and section properties of barrier models: (a) M1; (b) Slip Block-out of M6; (c) M5.

\section{SB5-B 등급 반-강성 배리어 결정}

\section{1 배리어 모델 1(M1)}

배리어 모델 1에 대하여 Computer Simulation을 이용 하여 성능평가를(탑승자 안전도, 구조적 적절성, 충돌 후 차량거동, 횡 변위 제한조건) 수행하였다. 배리어 모델 1(M1)은 SB5-B 대형차 충돌조건과 최대 횡 변위 조건 ( $1 \mathrm{~m})$ 을 만족시킬 수 있도록 예비설계 과정을 통해서 결 정되었다.

M1 모델에 충돌위치(Impact Point)를 변화시키며 $\mathrm{SB} 5-\mathrm{B}$ 소형차 충돌조건을 적용하는 $\mathrm{FEA}$ 를 수행하였다. 첫 번째 충돌위치(IP1)는 Post에서 우측으로 $0.65 \mathrm{~m}$ 이격 된 지점이고 두 번째부터 다섯 번째 충돌위치(IP2 IP5) 는 IP1에서 $0.5 \mathrm{~m}$ 씩 순차적으로 우측으로 이동된 지점이 다. 충돌위치에 상관없이 $t_{T}$ 에서 종방향 차량 이동 거리 는 약 $2.5 \mathrm{~m}$ 로 나타났다.

THIV가 가장 크게 나타나는 Critical Impact Point(CIP)는 지주에서 $2.15 \mathrm{~m}$ 만큼 이격된 IP4 이고 IP4 에 대한 $T H I V$ 는 $37.0 \mathrm{~km} / \mathrm{h}$ 로 나타났다. CIP에 대한 $T H I V$ 기준 $(33 \mathrm{~km} / \mathrm{h})$ 을 만족시키기 위하여 충돌초기에 차 량 횡변위를 감소시킬 필요가 있다. 충돌초기의 작은 횡 
변위는 $t_{T}$ 근처에서 $V_{x}$ 에 미치는 지주의 영향을 줄이고 충돌초기의 $V_{y}$ 기울기를 증가시킬 것이다. 또한 $t_{T}$ 근 처에서 $V_{y}$ 기울기가 증가하지 않도록 지주 횡방향 강성 의 영향을 최소화 할 필요가 있다.

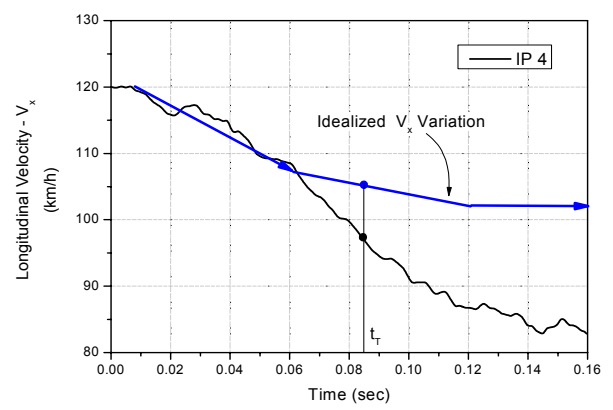

(a)

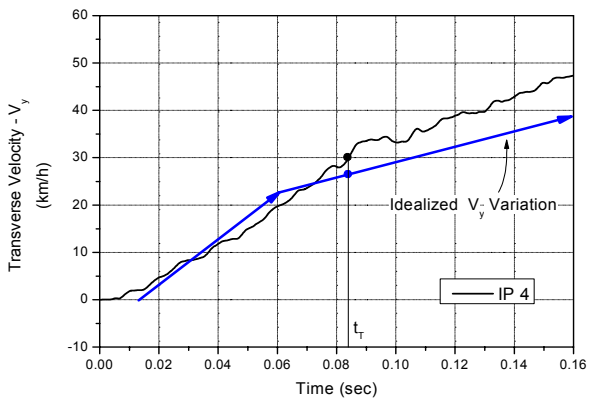

(b)

[Fig. 3] Simulation results for M1: (a) Comparison of $V_{x}$ variation of IP4 and Idealized $V_{x}$ Variation ; (b) Comparison of $\mathrm{V}_{\mathrm{y}}$ variation of IP4 and Idealized $\mathrm{V}_{\mathrm{y}}$ Variation

$\mathrm{M} 1$ 모델에 대하여 SB5-B 대형차 충돌조건을 적용하 여 simulation을 수행하였다. 차량모델은 NCAC에서 공개 하고 있는 유럽 표준 $\mathrm{EN}-1317$ 시험 차량 모델 $\mathrm{HGV}$ 16 ton을 사용하였다. 차량 질량은 $\mathrm{HGV} 16$ ton 모델에 무 게중심 $(\mathrm{CG})$ 이 변하지 않도록 절점질량을 감소시켜서 14 ton으로 수정하였다. SB5-B 대형차 충돌조건을 적용한 $\mathrm{M} 1$ 모델의 Simulation에 의한 최대 횡변위는 $1.19 \mathrm{~m}$ 로 나 타났고 충돌차량이 하단 보를 밟고 지나가면서 구조적으 로 매우 불안정한 거동을 보였다. 대형차 충돌조건에 대 한 횡변위 제한조건을 고려하여 횡변위를 $0.8 \mathrm{~m}$ 로 가정하 고 Olson Model을 이용하여 대형차 충돌시 발생하는 횡 방향력을 산정하면 19.0ton으로 나타난다. 대형차 충돌시 발생하는 횡방향력 보다 배리어 극한강도를 크게 만들기 위하여 보 단면적을 증가시키며 Failure Mechanism을 적
용하면 상,하 단 보의 두께가 $7 \mathrm{~mm}$ 이상 되어야 배리어 극 한강도가 19.0ton이상이 된다. 또한 상,하단 보 두께를 $7 \mathrm{~mm}$ 로 증가시킨다면 CIP에 대한 소형차 충돌시 차량 횡 변위를 감소시킬 수 있다고 판단된다. 충돌초기의 작은 횡변위는 Fig. 3(a)와 같이 $t_{T}$ 근처에서 $V_{x}$ 증가를 방지 할 수 있고 Fig. 3(b)와 같이 충돌초기의 $V_{y}$ 기울기를 증 가시킬 수 있기 때문에 소형차 충돌위치 변화에 대한 $T H I V$ 편차를 감소시킬 수 있을 것으로 판단된다.

\section{2 배리어모델 2(M2)}

$\mathrm{M} 2$ 모델은 M1 모델의 상,하단 보 두께를 기존의 $4 \mathrm{~mm}, 5 \mathrm{~mm}$ 에서 각각 $7 \mathrm{~mm}$ 로 증가시킨 모델이다. Fig. 4(a)에 나타나 있는 IP4의 M2 모델과 M1 모델의 $V_{x}$-시 간 이력을 비교하여 보면 충돌초기에는 기울기가 유사하 지만 $t_{T}$ 근처에서는 $\mathrm{M} 2$ 모델의 기울기가 $\mathrm{M} 1$ 모델 보다 크게 감소하는 것을 알 수 있다. M2 모델의 경우 보의 횡 방향 강성이 M1 모델 보다 크게 증가하여 충돌초기에 차 량 횡변위가 크게 감소하게 된다. 따라서 $t_{T}$ 근처에서 $V_{x}$ 에 미치는 지주 영향이 작아지게 되어 $\mathrm{M} 2$ 모델의 $V_{x}$ 기울기가 $\mathrm{M} 1$ 모델 보다 상당히 감소하게 된다. 결론 적으로 충돌위치에 상관없이 보 강성 증가로 인하여 M2 모델의 $t_{T}$ 와 $V_{x}\left(t_{T}\right)$ 가 $\mathrm{M} 1$ 모델 보다 작게 나타난다.

Fig. 4(b)에 나타나있는 M1 모델과 M2 모델의 IP4에 대한 $V_{y}$-시간 이력을 비교하여보면 전체적으로 M2 모 델의 $V_{y}$ 기울기가 $\mathrm{M} 1$ 모델의 기울기 보다 상당히 크게 나타나는 것을 알 수 있다. 보 강성이 증가하면 배리어 전체 강성도 증가하기 때문에 지주 횡방향 강성이 $V_{y}$ 를 주로 지배하는 시간(IP1의 충돌초기와 IP4의 $t_{T}$ 근처)에 서도 $\mathrm{M} 2$ 모델의 $V_{y}$ 기울기가 M1 모델 보다 상당히 크 게 증가하였다. 따라서 보 강성이 증가된 M2 모델은 IP 에 상관없이 $V_{y}$ 기울기가 증가되기 때문에 $\mathrm{M} 1$ 모델 보 다 $t_{T}$ 가 단축되고 $V_{y}\left(t_{T}\right)$ 는 증가하게 된다. 결론적으 로 $\mathrm{M} 2$ 모델의 $\operatorname{THIV}(34.6 \mathrm{~km} / \mathrm{h})$ 는 $\mathrm{M} 1$ 모델 보다 상당히 감소하였다.

$\mathrm{SB} 5-\mathrm{B}$ 소형차 충돌조건에 대하여 M2 모델의 보 두께 를 변화시켜서 $T H I V$ 한계값이 만족될 수 있는지 보 강 성의 영향이 더 조사 되었다. 모델의 변화로 인해 발생하 는 $V_{x}\left(t_{T}\right)$ 의 감소(- $\left.\Delta V_{x}\left(t_{T}\right)\right)$ 와 $V_{y}\left(t_{T}\right)$ 의 증가 $(+$ $\left.\Delta V_{y}\left(t_{T}\right)\right)$ 로 인하여 $T H I V$ 가 감소하기 위해서는 식(1) 이 만족되어야 한다. 


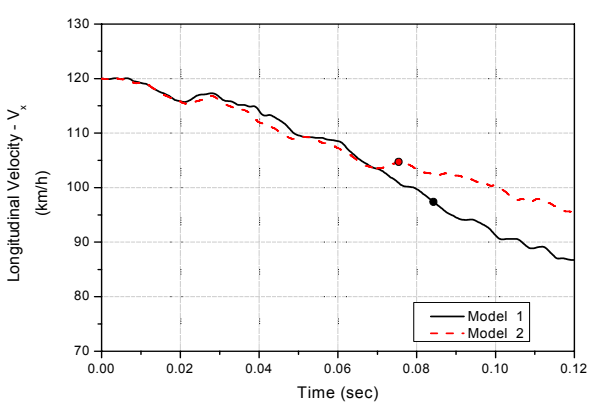

(a)

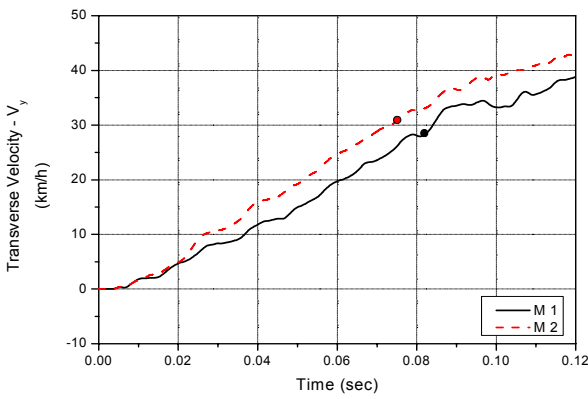

(b)

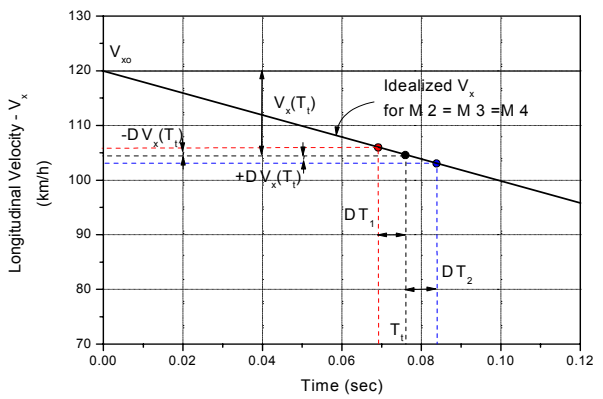

(c)

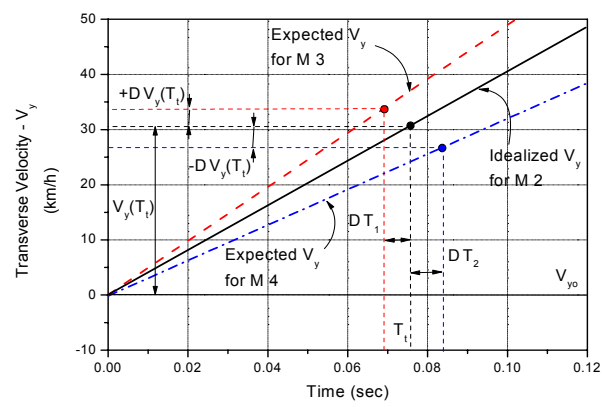

(d)

[Fig. 4] Simulation results for IP4: (a) $\mathrm{V}_{\mathrm{x}}$ variation of M1 and M2; (b) $\mathrm{V}_{\mathrm{y}}$ variation of M1 and M2; (c) Idealized $\mathrm{V}_{\mathrm{x}}$ variation; (d) Idealized $\mathrm{V}_{\mathrm{y}}$ variation.
식(1)을 $\Delta V_{x}\left(t_{T}\right) / \Delta V_{y}\left(t_{T}\right)$ 와 $V_{y}\left(t_{T}\right) / V_{x}\left(t_{T}\right)$ 의 항으로 정리하면 식(2)와 같다. 식(2)에서 부등호 우측의 두 번째 항이 항상 양수이기 때문에 이항을 무시하고 일 반적으로 나타나는 횡방향 속도에 대한 종방향 속도의 비 $V_{y}\left(t_{T}\right) / V_{x}\left(t_{T}\right)=2$ 를 대입하면 $T H I V$ 가 감소하기 위해서는 $\Delta V_{x}\left(t_{T}\right) / \Delta V_{y}\left(t_{T}\right)$ 가 최소 2 이상 되어야 한 다는 것을 알 수 있다.

$$
\begin{aligned}
& \frac{\sqrt{V_{x}^{2}\left(t_{T}\right)+V_{y}^{2}\left(t_{T}\right)}>}{\sqrt{\left(V_{x}\left(t_{T}\right)-\Delta V_{x}\left(t_{T}\right)\right)^{2}+\left(V_{y}\left(t_{T}\right)+\Delta V_{y}\left(t_{T}\right)\right)^{2}}} \\
& \frac{\Delta V_{x}\left(t_{T}\right)}{\Delta V_{y}\left(t_{T}\right)}>\frac{V_{y}\left(t_{T}\right)}{V_{x}\left(t_{T}\right)}+\frac{\Delta V_{x}\left(t_{T}\right)^{2}+\Delta V_{y}\left(t_{T}\right)^{2}}{2 V_{x}\left(t_{T}\right) \Delta V_{y}\left(t_{T}\right)}
\end{aligned}
$$

Fig. 4(c)에 M2 모델에 대한 이상화된 $V_{x}$-시간 이력 이 나타나 있고 Fig. 4(d)에는 M2 모델에 대한 이상화된 $V_{y}$-시간 이력과 보 두께를 $\mathrm{M} 2$ 모델 보다 증가시켰을 경 우(M3)에 예상되는 $V_{y}$-시간 이력의 비교가 나타나 있다. $\mathrm{M} 1$ 모델 보다 보 두께가 증가된 $\mathrm{M} 2$ 모델의 경우에 $V_{x}$ 기울기가 M1 모델과 유사하였기 때문에 M2 모델 보다 보 두께가 증가된 $\mathrm{M} 3$ 모델의 경우에도 $V_{x}$ 기울기가 $\mathrm{M} 2$ 모델과 유사할 것으로 예상된다. M1 모델 보다 보 두께 가 증가된 $\mathrm{M} 2$ 모델의 $V_{y}$ 기울기는 전체적으로 $\mathrm{M} 1$ 모델 보다 증가하기 때문에 $\mathrm{M} 3$ 모델의 경우에도 $V_{y}$ 기울기 가 $\mathrm{M} 2$ 모델 보다 증가하고 $t_{T}$ 도 단축될 것으로 예상된 다. $\mathrm{M} 3$ 모델의 경우에 보 두께 증가로 인한 $T H I V$ 변화 를 파악하기 위하여 Fig. 4(c)와 Fig. 4(d)의 $V_{x}$-시간 이 력과 $V_{y}$-시간 이력에 삼각형의 닮음비를 적용하면 $\Delta V_{x}\left(t_{T}\right)$ 와 $\Delta V_{y}\left(t_{T}\right)$ 의 비가 식(3)과 같이 표현될 수 있다. 식(3)으로부터 $V_{x}\left(t_{T}\right) / V_{y}\left(t_{T}\right)$ 이 $1 / 2$ 정도인 일반 적인 경우에 $V_{y}$ 기울기(혹은 $\Delta T_{1}$ )가 증가할수록 $\mathrm{M} 3$ 모델에 대한 $\Delta V_{x}\left(t_{T}\right) / \Delta V_{y}\left(t_{T}\right)$ 가 $1 / 2$ 보다 작아진다 는 것을 알 수 있다. 따라서 $T H I V$ 가 감소되기 위해서는 앞에서 설명한 바와 같이 일반적인 $V_{y}\left(t_{T}\right) / V_{x}\left(t_{T}\right)$ 에 대해서 $\Delta V_{x}\left(t_{T}\right) / \Delta V_{y}\left(t_{T}\right)$ 가 2 보다 커야 하기 때문에 보 두께를 $\mathrm{M} 2$ 모델 보다 증가시켜서 $T H I V$ 를 감소시키 는 것은 현실적으로 어려울 것으로 판단된다.

$$
\frac{\Delta V_{x}\left(t_{T}\right)}{\Delta V_{y}\left(t_{T}\right)}=\frac{V_{x}\left(t_{T}\right)}{V_{y}\left(t_{T}\right)} \cdot \frac{t_{T}-\Delta T_{1}}{t_{T}}
$$


M1 모델 보다 보 두께가 감소한다면 대형차 충돌조건 에 대하여 구조적 적절성이 취약해지고 횡변위가 증가될 것이다. 또한 소형차 충돌조건에 대해서도 지주와 보의 강성 차이가 M1 모델 보다 커지기 때문에 IP에 따른 $T H I V$ 의 차이와 지주에서 상당히 떨어진 IP에 대한 $T H I V$ 가 $\mathrm{M} 1$ 모델 보다 증가할 것이다. 따라서 보 두께 를 증가시키거나 감소시키는 방법으로 SB5-B 충돌조건 을 만족시키는 배리어를 개발하는 데에는 한계가 있다고 판단된다.

$V_{x}$ 기울기를 변화시키지 않고 $V_{y}$ 기울기를 감소시 켜서 $T H I V$ 를 감소시킬 수 있는지 Fig. 4(c)와 Fig. 4(d)에 나타나 있는 M4 모델에 대하여 예측되는 $V_{x}$-시 간 이력과 $V_{y}$-시간 이력을 이용하여 검토하였다. M4 모 델은 $V_{y}$ 기울기가 감소할수록 $T H I V$ 가 결정되는 시간 $t_{T}$ 가 증가하고 $V_{y}\left(t_{T}\right)$ 는 감소하며 $V_{x}\left(t_{T}\right)$ 는 증가하게 된다. $\mathrm{M} 3$ 경우와 반대로 $\mathrm{M} 4$ 모델은 $V_{x}$ 기울기가 변화하 지 않으면서 $V_{y}$ 기울기가 감소되기 때문에 항상 $\mathrm{M} 2$ 모 델에 비하여 $T H I V$ 가 줄어들 것이다. $\mathrm{M} 2$ 모델에 비교하 여 $V_{x}$ 기울기를 유사하게 유지하며 $V_{y}$ 기울기를 감소 시키기 위한 효과적인 방법은 M2 모델의 보와 지주의 강 성을 그대로 유지하며 $V_{x}$ 기울기 변화에 민감하게 작용 하지 않는 Block-Out을 M2 모델 보다 유연하게 조정하는 것이다. 보와 지주의 연결의 구속정도를 나타내는 Block-Out의 강성을 M2 모델 보다 작게하면 배리어의 전 체 강성이 작아지고 $V_{y}$ 기울기가 감소 될 것으로 예측된 다. Block-Out의 강성을 M2 모델 보다 작게할 때 대형차 충돌조건에 대한 최대 횡변위가 크게 증가되지 않고 IP 변화에 따라 $V_{x}$ 기울기 차이가 크게 나타나지 않도록 유의할 필요가 있다. Block-Out의 길이와 Block-Out이 보 를 지지하는 길이를 증가시키면 Block-Out의 강성이 감 소되고 보의 순경간이 감소되어 IP의 변화에 따른 $V_{x}$ 기 울기의 차이가 줄어들 것으로 예측된다.

\section{3 배리어모델 4(M4)}

M4 모델은 M2 모델에 대하여 하단 Block-Out의 길이 를 증가시키고 지지 길이를 확대시킨 모델이다. M4 와 $\mathrm{M} 2$ 모델에 적용된 Block-Out의 형상과 에너지 소산성능 이 Fig. 5(a)에 나타나 있다.

Fig. 5(b)에 나타나 있는 M2 모델과 M4 모델의 $V_{x}$ 시간 이력을 비교하여 보면 M4 모델의 $V_{x}$ 기울기가 M2 모델의 $V_{x}$ 기울기와 대체적으로 유사하였다. Fig. 5(c)에
는 $\mathrm{M} 2$ 와 $\mathrm{M} 4$ 모델에 대한 $V_{y}$-시간 이력이 나타나 있는 데 $\mathrm{M} 4$ 의 $V_{y}$ 기울기가 $\mathrm{M} 2$ 모델 보다 작게 나타났고 $\mathrm{M} 4$ 모델의 $t_{T}$ 가 $\mathrm{M} 2$ 모델 보다 지체되었다. $V_{x}$ 기울기가 유 사한 경우에 보다 큰 $t_{T}$ 를 갖는 $\mathrm{M} 4$ 모델의 $V_{x}\left(t_{T}\right)$ 가 $\mathrm{M} 2$ 모델 보다 크게 나타났고 $V_{y}$ 기울기가 작은 $\mathrm{M} 4$ 모 델의 $V_{y}\left(t_{T}\right)$ 는 $\mathrm{M} 2$ 모델 보다 감소하였다. 따라서 예상 한 바와 같이 M4 모델의 $\operatorname{THIV}(33.1 \mathrm{~km} / \mathrm{h})$ 는 $\mathrm{M} 2$ 모델 보다 감소하였다.

$\mathrm{M} 4$ 모델 보다 $T H I V$ 를 더 감소시키기 위해서 $V_{x}$ 기 울기를 변화시키지 않고 $V_{y}$ 기울기를 더 감소시킬 수 있 도록 Block-Out의 길이를 더 증가시킨다면 보 무게로 인 하여 Block-Out의 아래방향 비틀림이 발생할 수 있고 배 리어 설치 폭의 제약이 있는 경우에는 적용하는데 어려 움이 있을 수 있다. 따라서 Fig. 6(a)와 Fig. 6(b)에 나타나 있는 것과 같이 $\mathrm{M} 4$ 모델 보다 $V_{x}$ 기울기를 전체적으로 감소시키고 충돌초기의 $V_{y}$ 기울기를 증가시키면서 $t_{T}$ 근처의 $V_{y}$ 기울기를 감소시키는 방안(M5)이 고려되었 다. 이 방안이 의도한 바와 같이 이루어진다면 M4 모델 보다 $V_{x}\left(t_{T}\right)$ 와 $V_{y}\left(t_{T}\right)$ 가 모두 감소하고 결과적으로 $T H I V$ 가 상당히 작아질 것으로 예상된다.

2 개의 보가 사용된 M4 모델에 대하여 보 면적만을 증 가시킨다면 충돌초기와 $t_{T}$ 근처의 $V_{y}$ 기울기가 모두 증 가 할 수 있기 때문에 전체 보 면적을 증가 시키면서 승 용차 충돌하중을 주로 받는 보의 면적을 감소시키기 위 하여 3 개의 보를 고려할 수 있다. 승용차 충돌하중이 집 중되는 보의 면적을 M4 모델 보다 감소시킨다면 대체적 으로 $t_{T}$ 근처의 $V_{y}$ 기울기를 감소시킬 수 있을 것으로 예상된다. 또한 전체 보 면적이 M4 모델 보다 증가된다 면 충돌초기에 $\mathrm{Yaw}$ 각도 변화가 커지게 되어 $V_{x}$ 기울 기가 작아질 수 있을 것으로 예측된다.

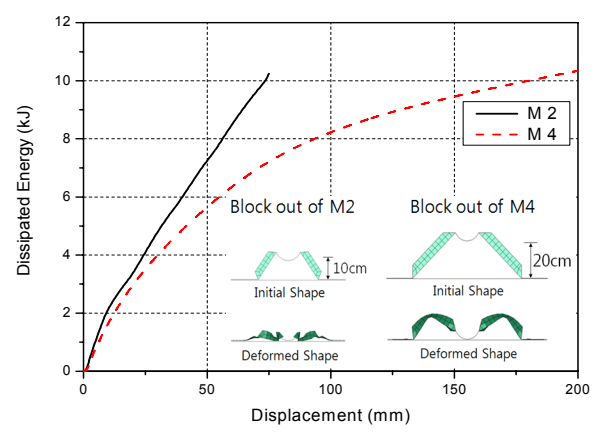

(a) 


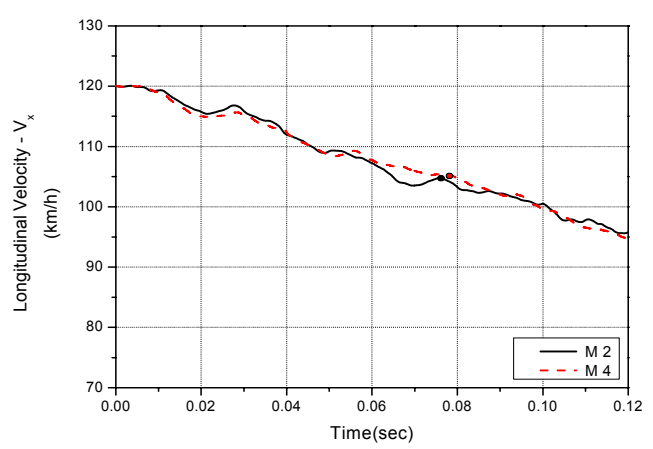

(b)

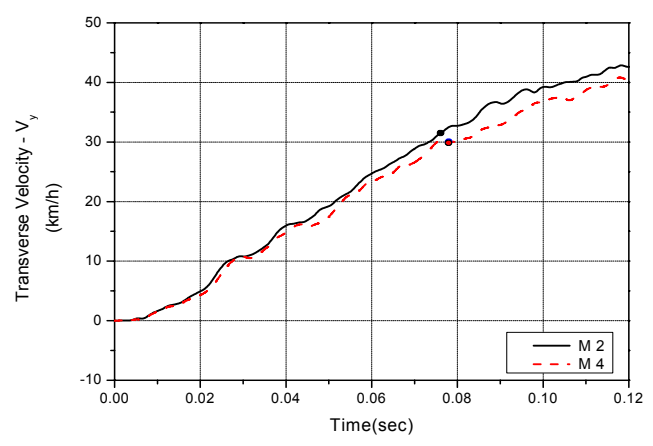

(c)

[Fig. 5] Simulation results for IP4: (a) Block-Out shapes and capacites of energy dissipation for M2 and M4; (b) $V_{x}$ variation of M2 and M4; (c) $V_{y}$ variation of M2 and M4.

\section{4 배리어 모델 5(M5)}

M5 모델에는 배리어 전체 강성이 M4 모델 보다 증가 되도록 M4 모델의 2 개의 보 보다 면적이 $15 \%$ 증가된 3 개의 보가 사용되었고 승용차 충돌하중이 집중되는 하단 보에 대해서 M5 모델에 M4 모델 보다 $11 \%$ 작은 면적이 사용되었다. 승용차 충돌하중을 주로 받는 보에 사용되는 M5 모델의 Block-Out은 M4 모델의 하단 보에 사용된 Block-Out과 유사하게 결정되었다. 중간 보의 변형이 하 단 보에 비하여 작게 나타나도록 중간보와 중간보 Block-Out은 하단보와 하단보 Block-Out 보다 작은 강성 을 갖게 하였다. 그리고 상단보의 Block-Out은 M4 모델 보다 큰 강성을 갖도록 하였다. 3 개의 보에 대한 보면적 의 상대비와 Block-Out 강성의 상대비는 여러번의 시뮬 레이션을 통하여 의도한 $V_{x}$ 기울기와 $V_{y}$ 기울기를 얻 도록 결정되었다.

Fig. 6(a)와 Fig. 6(b)를 살펴보면 M5 모델이 $V_{x}$ 기울 기가 M4 모델 보다 전체적으로 작게 나타나고 $V_{y}$ 기울
기는 충돌초기에 증가하고 $t_{T}$ 근처에서 작게 나타났다. 따라서 IP4를 제외하고 예상한 바와 같이 M5 모델의 $T H I V(32.2 \mathrm{~km} / \mathrm{h})$ 가 $\mathrm{M} 4$ 모델의 $T H I V$ 와 $T H I V$ 한계값 $(33 \mathrm{~km} / \mathrm{h})$ 보다 작게 나타났다. IP4에 대한 M5 모델의 $V_{x}$ 와 $V_{y}$ 기울기는 $\mathrm{M} 4$ 모델의 기울기와 유사하게 나타 났다. IP4의 경우 IP가 지주에서 상당히 떨어져있기 때문 에 충돌초기에 다른 IP 보다 하단보의 영향이 크게 나타 난다. 따라서 충돌초기에 전체 강성 증가로 인한 $V_{x}$ 기 울기 감소와 $V_{y}$ 기울기 증가가 나타나지 않았다. 그리고 $t_{T}$ 근처에서 지주의 영향이 크게 나타나 하단보의 면적 이 감소되었음에도 불구하고 $V_{y}$ 기울기의 감소가 나타 나지 않았다. 지주의 영향이 크게 나타난 것은 하단보의 면적이 감소하였고 보와 Block-Out의 연결이 강(Stiff)하 게 유지되어서 $t_{T}$ 근처에서 상대 횡변위의 차이가 크게 발생하였기 때문으로 판단된다.

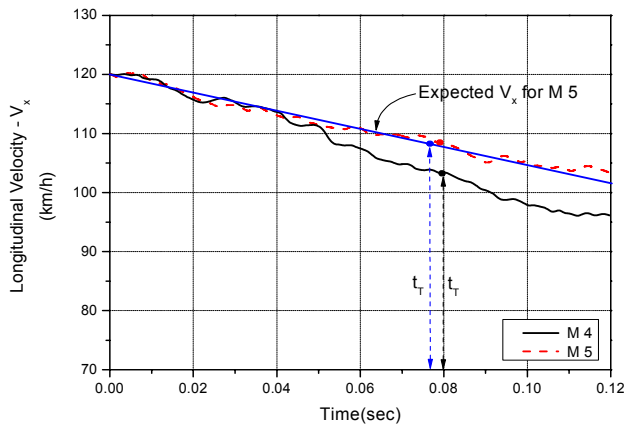

(a)

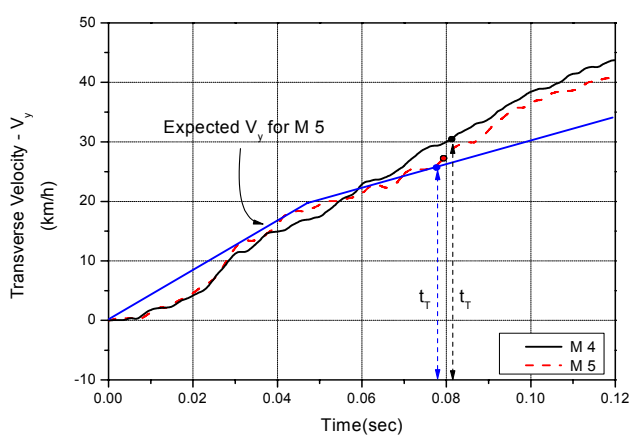

(b)

[Fig. 6] Simulation results for IP1: (a) $V_{x}$ variation of M4 and M5; (b) $V_{y}$ variation of M4 and M5.

IP4의 경우에 IP가 지주에서 상당히 떨어져 있기 때문 에 전체 보 면적을 유지하고 하단 보 면적을 증가시켜서 
충돌초기의 $V_{y}$ 기울기를 증가시키기는 쉽지 않다. 그리 고 하단보 면적의 증가는 $t_{T}$ 근처에서 $V_{y}$ 기울기를 증 가시켜서 $T H I V$ 가 증가될 것이다. 또한 전체 보 면적을 유지하면서 하단보 면적을 M5 모델 보다 감소시킨다면 $t_{T}$ 근처에서 지주의 영향이 더 크게 나타나 THIV가 증 가하게 될 것으로 예상된다. 따라서 IP4에 대하여 $T H I V$ 를 감소시키기 위하여 충돌초기에 $V_{x}$ 와 $V_{y}$ 기울기를 M5 모델의 기울기와 유사하게 유지하고 $t_{T}$ 근처에서는 $V_{x}$ 와 $V_{y}$ 기울기를 $\mathrm{M} 5$ 의 기울기보다 감소시키는 방안 (M6)이 고려되었다.

차량이 지주에 접근하는 쪽의 보와 Block-Out의 연결 을 충돌초기에 M5 모델의 연결과 유사하게 유지하고 $t_{T}$ 근처에서 유연하게 거동하게 한다면 IP4에 대하여 충돌 초기에 M5 모델과 유사한 $V_{x}$ 와 $V_{y}$ 기울기를 유지할 수 있고 $t_{T}$ 근처에서 상대 횡변위를 감소시켜 $V_{x}$ 와 $V_{y}$ 기울기를 M5 모델 보다 감소시킬 수 있을 것으로 예상된 다. 차량이 지주에 접근하는 쪽의 보와 Block-Out의 연결 을 Slip 형으로 구성한다면 충돌초기에 M5 모델의 연결 과 유사한 거동이 나타나고 $t_{T}$ 근처에서 유연한 거동이 이루어 질 수 있다고 예상된다.

\section{5 배리어모델 6(M6)}

$\mathrm{M} 6$ 모델은 차량이 지주에 접근하는 쪽의 보와 Block-Out의 연결이 초기 충돌하중에 의한 변형으로 인 하여 Slip이 발생하는 비대칭 Block-Out이 적용된 모델이 다. IP4에 대한 M5 모델과 M6 모델의 $V_{x}$-시간 이력 비 교가 나타나 있는 Fig. 7(a)와 $V_{y}$-시간이력 비교가 나타 나 있는 Fig. 7(b)를 살펴보면 IP4에 대하여 충돌초기에 $\mathrm{M} 6$ 모델의 $V_{x}$ 와 $V_{y}$ 기울기가 M5 모델과 유사하고 $t_{T}$ 시간 근처에서 M5 모델 보다 감소하는 것을 알 수 있다. $\mathrm{M} 6$ 모델의 IP4에 대한 $T H I V(30.6 \mathrm{~km} / \mathrm{h})$ 가 $T H I V$ 한계 값 보다 $7 \%$ 작게 나타났고 $T H I V$ 가 가장 크게 나타난 $\mathrm{IP} 3$ 에 대해서도 $T H I V$ 가 한계값 보다 $4 \%$ 작게 나타나 $\mathrm{M} 6$ 모델이 SB5-B 소형차 충돌조건을 성공적으로 만족 하였다. Simulation을 통하여 성능이 검증된 M6 모델에 대하여 실물차량 충돌시험이 수행되었다. M6 모델의 $\mathrm{SB} 5-\mathrm{B}$ 소형차 충돌조건에 대한 $T H I V$ 는 $29.9 \mathrm{~km} / \mathrm{h}$ 로 나 타나 한계값 $(33 \mathrm{~km} / \mathrm{h})$ 보다 $9 \%$ 작게 나타났고 $P H D$ 는 한계값 $(20 \mathrm{~g})$ 보다 상당히 작은 $10.5 \mathrm{~g}$ 이었다. 보다 자세한 실물충돌시험 결과는 참고문헌[4]에 나타나있다.

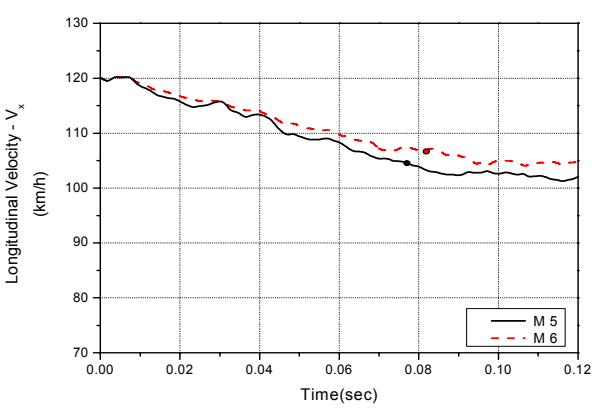

(a)

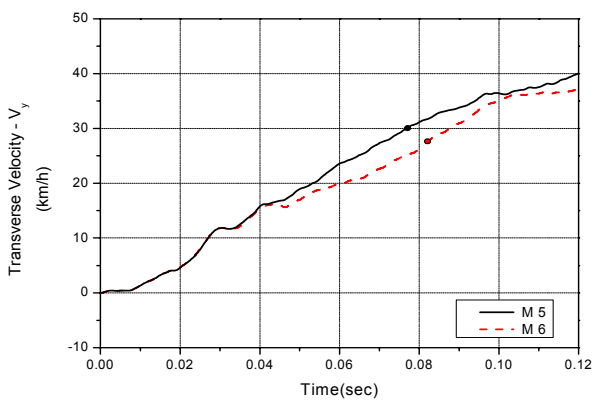

(b)

[Fig. 7] Simulation results for IP4: (a) $V_{x}$ variation of M5 and M6; (b) $V_{y}$ variation of M5 and M6.

\section{4. 형차 충돌속도 $130 \mathrm{~km} / \mathrm{h}$ 평가}

IP3에 대한 M6 모델의 $130 \mathrm{~km} / \mathrm{h}$ 소형차 충돌속도를 적용한 FEA에 의한 $T H I V$ 가 $33.8 \mathrm{~km} / \mathrm{h}$ 로 $T H I V$ 한계 $(33 \mathrm{~km} / \mathrm{h})$ 를 초과하였으나 초과된 값이 0.8 로 많이 크지 않기 때문에 $130 \mathrm{~km} / \mathrm{h}$ 의 소형차 충돌속도를 만족시킬 수 있는 배리어 개발이 가능하다고 판단되었다. M6 모델의 다른 구성요소는 변화시키지 않고 Block-Out 날개 각도 만을 변화시키면서 M6 모델의 $T H I V$ 를 감소시킬 수 있 는지 조사하였다. M6 모델의 Block-Out 날개와 보가 이 루는 각도는 $45^{\circ}$ 로 좌우측이 동일하다. Slip hole이 없는 Block-Out 날개의 각도를 감소시킨다면 Slip 기능은 유지 되면서 Block-Out 강성은 감소된다. 이러한 Block-Out 강 성의 감소는 전체 시스템 강성을 감소시키나 보의 강성 변화에는 영향을 주지 않기 때문에 차량 횡방향 속도-시 간 이력의 기울기가 전체적으로 감소되고 차량 종방향 속도 변화는 크지 않을 것으로 예상되었다. Block-Out 날 개각도 변화에 대한 영향을 살펴보기 위하여 Fig. 8의 Block-Out 날개각도 $20^{\circ}, 30^{\circ}$, 그리고 $60^{\circ}$ 경우에 대해서 $\mathrm{IP}$ 를 변화시키며 $\mathrm{FEA}$ 를 수행하였다. 다양한 slip 
Block-out 날개 각도를 적용한 모델에 대한 $130 \mathrm{~km} / \mathrm{h}$ 소 형차 충돌속도를 적용한 FEA에 의한 THIV가 Table. 2에 나타나 있다. 이 표로부터 날개각도가 감소함에 따라

$T H I V$ 가 감소함을 알 수 있다. 날개각도가 $20^{\circ}$ 인 경우 에 최대 $T H I V$ 가 IP3에서 $32.2 \mathrm{~km} / \mathrm{h}$ 로 나타났다. 이러 한 결과로부터 $120 \mathrm{~km} / \mathrm{h}$ 의 SB5-B 소형차 충돌속도를 $130 \mathrm{~km} / \mathrm{h}$ 로 상향시킬 수 있는 가능성이 커진 것을 알 수 있다.

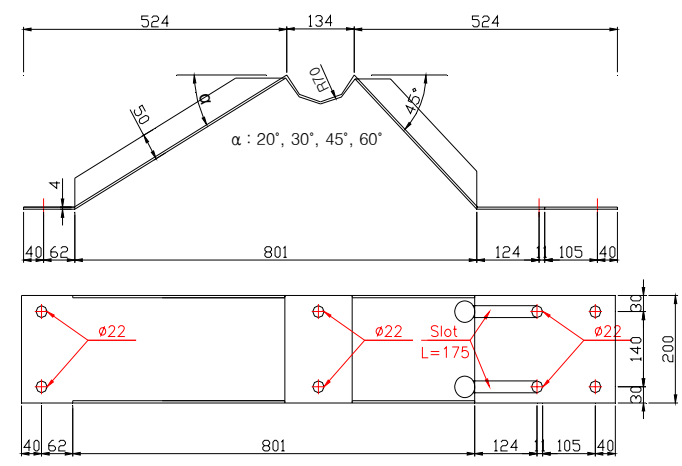

[Fig. 8] Wing angles of Slip Block-Out wing

$30^{\circ}$ 의 Block-out 날개각도가 적용된 수정 M6모델에 대하여 충돌속도 $130 \mathrm{~km} / \mathrm{h}$, 충돌차량 질량 $900 \mathrm{~kg}$, 충돌각 도 $20^{\circ}$ 를 적용한 실물충돌 시험이 수행되었다. Fig. 9에 수정 M6에 대한 실물충돌시험 형상이 나타나 있다. 실물 충돌시험의 $T H I V$ 는 $33.9 \mathrm{~km} / \mathrm{h}$ 이고 $P H D$ 는 $19.1 \mathrm{~g}$ 로 나 타났다. $T H I V$ 가 한계값을 $0.9 \mathrm{~km} / \mathrm{h}$ 초과하였는데 그 이 유는 다음과 같은 사실 때문인 것으로 판단된다. $130 \mathrm{~km} / \mathrm{h}$ 의 충돌속도가 국내에서 처음으로 적용되었기 때문에 아스팔트나 콘크리트 포장면이 아닌 Fig.9에 보이 는 것과 같이 포장이 없는 성토부에서 충돌시험이 실시 될 수밖에 없었다. 포장면과 타이어의 일반적인 마찰거동 과 다른 거동이 나타났고 충돌속도와 충돌각도가 계획된 값보다 크게 나타나 $T H I V$ 에 부정적인 영향을 준 것으 로 판단된다. $20^{\circ}$ 의 날개각도에 대한 $\mathrm{FEA}$ 의 THIV가 $32.2 \mathrm{~km} / \mathrm{h}$ 이고 $30^{\circ}$ 의 날개각도에 대하여 여건이 좋지 않 은 실물충돌시험에 의해서도 $T H I V$ 가 $33.9 \mathrm{~km} / \mathrm{h}$ 인 점을 고려할 때 $130 \mathrm{~km} / \mathrm{h}$ 에 대한 표준시험 여건이 갖추어 진다 면 $120 \mathrm{~km} / \mathrm{h}$ 의 SB5-B 소형차 충돌속도를 $130 \mathrm{~km} / \mathrm{h}$ 로 상 향시킬 수 있는 가능성이 높다는 것을 알 수 있다. 보다 자세한 해석결과와 실물충돌 시험결과는 참고문헌[5]을 참조할 수 있다.
[Table 2] THIV of Various Slip Block-Out wing angles for Impact velocity $130 \mathrm{~km} / \mathrm{h}$

\begin{tabular}{c|c}
\hline $\begin{array}{c}\text { Slip Block-Out } \\
\text { Wing angle }\end{array}$ & $T H I V(\mathrm{~km} / \mathrm{h})$ \\
\hline \hline 20 & $32.2<33.0$ \\
\hline 30 & $33.0<33.0$ \\
\hline 45 & $33.8>33.0$ \\
\hline 60 & $34.1>33.0$ \\
\hline
\end{tabular}

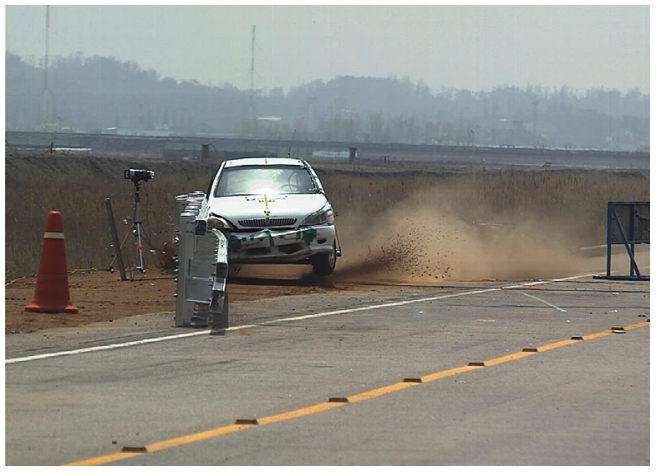

[Fig. 9] Full-scale crash test using the small car impact speed of $130 \mathrm{~km} / \mathrm{h}$

\section{5. 결론}

본 연구에서는 SB5-B 대형차 충돌조건을 만족하면서 $120 \mathrm{~km} / \mathrm{h}$ 의 SB5-B 소형차 충돌속도를 $130 \mathrm{~km} / \mathrm{h}$ 로 상향시 킬 수 있는 가능성을 조사하고자 하였다. 실물차량 충돌 시험에 calibrate된 입력변수를 이용한 컴퓨터 시뮬레이션 을 통하여 $120 \mathrm{~km} / \mathrm{h}$ 의 SB5-B 소형차 충돌속도에 대한 차 량의 종방향과 횡방향 속도변화가 $T H I V$ 한계를 만족시 킬 수 있도록 다양한 배리어 모델이 개선되었고 이 과정 을 통해 결정된 배리어 모델이 SB5-B 실물충돌시험을 통 과하였다. 통과된 배리어 모델 slip Block-out 날개의 각 도를 변화시키면서 $120 \mathrm{~km} / \mathrm{h}$ 소형차 충돌속도의 상향가 능성을 $\mathrm{FEA}$ 을 통하여 조사하고 실물차량 충돌시험을 수 행하였다. 소형차충돌속도 $130 \mathrm{~km} / \mathrm{h}$ 에 대한 표준시험 여 건이 갖추어 진다면 소형차 충돌속도 $130 \mathrm{~km} / \mathrm{h}$ 로 상향시 킬 수 있는 가능성이 높은 것으로 조사되었다.

\section{References}

[1] Fitzpatrick, Kay, "Criteria for High Design Speed Facilities", texas transportation institute, 2007. 
[2] LSTC, LS-DYNA Keyword User's Manual, Livermore Software Technology Corporation, Calf., 2007.

[3] NCAC, Public Finite Element Model Archive. National Crash Analysis Center(www.ncac.gwu.edu), Washington, D.C., 2011.

[4] K.D. Kim, M.G. Ko, D.S. Kim, J.W. Joo and D.Y. Jang, "Design of High-Performance Longitudinal Flexible Barrier Using Vehicle Velocity-time History", Journal of KOSHAM, Vol. 12, No. 3, pp. 157-167, 2012.

DOI: http://dx.doi.org/10.9798/KOSHAM.2012.12.3.157

[5] Ministry of Land, Infrastructure, and Transport, "Development of Road Safety Technologies for SMART Highway”, $2^{\text {nd }}$ Report, Korea, 2012.

\section{김 기 동(Kee-Dong Kim)}

[정회원]

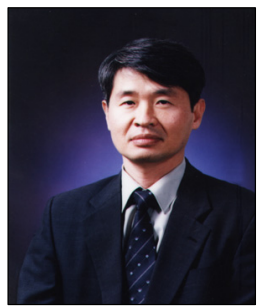

- 1985년 2월 : 고려대학교 토목공 학과(공학사)

- 1989년 2월 : 오클라호마 주립대 토목구조전공(공학석사)

- 1995년 5월 : 텍사스주립대(오스 틴) 토목구조전공 (공학박사)

- 1997년 10월 현재 : 공주대학 교 건설환경공학부 교수

<관심분야>

교통안전, 구조공학, 내진공학

고 만 기(Man-Gi Ko)

[정회원]

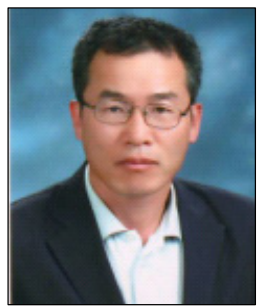

- 1981년 2월 : 서울대학교 농공학 과(공학사)

- 1988년 8월 : 오클라호마 주립대 토목공학전공(공학석사)

- 1992년 12월 : Texas A\&Meo 토목공학전공(공학박사)

- 1998년 4월 현재 : 공주대학 교 건설환경공학부 교수

<관심분야>

교통안전, 교량공학 